\title{
CORRECTIONS
}

\section{Author Correction: Microbial niches in marine oxygen minimum zones}

\section{Anthony D. Bertagnolli and Frank J. Stewart}

Nature Reviews Microbiology (2018) https://doi.org/10.1038/s41579-018-0087-z

Published online 24 September 2018

In Figure 3, 'Candidatus Scalindua' and Thaumarchaeota were erroneously shown to produce nitrous oxide $\left(\mathrm{N}_{2} \mathrm{O}\right)$. As neither group directly produces $\mathrm{N}_{2} \mathrm{O}$, the arrows and products have been removed both online and in the pdf. The authors apologize for any confusion caused.

https://doi.org/10.1038/s41579-018-0103-3 I Published online 8 October 2018 